\title{
O novo na sociologia latino-americana
}

\section{LUCIO OLIVER COSTILLA}

\section{A especificidade sociocultural atual da América Latina}

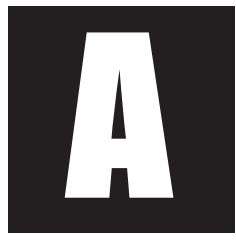

mérica Latina é uma região que tem uma especificidade significativa no mundo atual. Ela tem uma população trabalhadora com efetiva atividade política e uma intelectualidade desenvolvida política e culturalmente que apresenta uma grande contradição com o seu perfil de subcontinente subdesenvolvido entregue ao capitalismo transnacional. A região hoje vivencia múltiplos problemas e dificuldades, submersa na estagnação de sua economia, na exclusão social crescente e no enfraquecimento de seus Estados.

A combinação contraditória no continente latino-americano entre uma intelectualidade que tem um elevado nível e a existência de movimentos sociais e políticos que atuam numa situação social explosiva, gera amplas possibilidades para o desenvolvimento da sociologia.

A sociologia latino-americana, como todas as ciências sociais, tem sido afetada pelas novas situações e fenômenos de fim de século: a revolução técnico-científica no âmbito de capitalismo industrial, a queda do socialismo estatal, os processos de mundialização do capital, a revalorização

\footnotetext{
* Doutor em Sociologia pela Universidade Nacional Autónoma do México. Professor titular do Centro de Estudos Latinoamericanos, Faculdade de Ciências Políticas e Sociais, Universidade Nacional Autónoma do México.
} 
das comunidades locais e dos grupos étnicos, o papel determinante do indivíduo e suas necessidades. Nesta medida, a crise das ciências sociais acompanha essas mudanças significativas, na busca de novas perspectivas analíticas capazes de explicar o ritmo de mudanças contemporâneas.

Dois Congressos da Associação Latino-americana de Sociologia -ALAS-,os realizados na Cidade do México, em 1995, e em São Paulo, em 1997, mostraram uma recuperação da teoria e da crítica no trabalho dos sociólogos, ante a crise das ciências sociais e o empirismo neoliberal. E mais, uma revisão das discussões de eventos acadêmicos significativos no Brasil mostram esta tendência revitalizadora: os trabalhos das comissões da ANPOCS, em função do encontro de 1996; os grupos de trabalho no Encontro de Ciências Sociais Norte/Nordeste, em Fortaleza, Ceará, 1997; os grupos de trabalho no VIII Congresso da Associação Brasileira de Sociologia, em Brasília, em 1997, o XIII Congresso em Campinas, em 2003.

A rigor, como novidade neste início de milênio, a Sociologia da América Latina apresenta uma acumulação de conhecimentos particulares nos mais variados âmbitos da vida social, o que se pode ver facilmente na diversidade de temáticas e grupos de trabalho nos referidos encontros. Muitas temáticas novas ficam, naturalmente, na ordem do dia para a sociologia: o papel das etnias, dos movimentos regionais, das lutas pelo aprofundamento da cidadania; a reconstituição dos pactos constitutivos do Estado e das nações; o papel desorganizador do narcotráfico; o neoautoritarismo no âmbito de processos democráticos; a exclusão social estrutural com o desemprego crescente; a corrupção; as crises dos sistemas políticos; a queda das utopias; os fundamentalismos; a democracia participativa nos municípios; os fenômenos associados a uma busca de qualidade de vida.

Em verdade, o que a sociologia latino-americana tem como novo é um regresso ao pensamento crítico que a caracterizou no passado recente e uma emergente tendência em estabelecer a devida relação dos estudos 
particulares com a dinâmica da totalidade social. Pelas particularidades da América Latina, a sociologia pode ir mais longe. Para isso, precisa aprofundar sua reflexão sobre as diferentes questões que se apresentam como objeto de estudo.

A importante recuperação da crítica no pensamento social latinoamericano $^{1}$ delimita, antes de tudo, uma postura política de contestação dos sociólogos, a exigir um avanço similar na elaboração da teoria social. De fato, a postura contestatória não implica, por si só, um desenvolvimento na reflexão e na análise dos problemas. Exige um esforço efetivo de elaboração e produção.

A questão do avanço teórico não pode associar-se, de novo, à tentativa de voltar a propor o domínio de uma teoria mais científica que as outras. A história dos dois últimos séculos demonstrou que, nas ciências sociais, é impossível a dominação absoluta de uma teoria ou de um paradigma único:

Dentro de uma disciplina formal, muitas grandes teorias podem co-habitar, mas existe um paradigma apenas quando uma teoria comprovável domina, sozinha, todas as outras teorias e é aceita pela comunidade cientifica como um todo. Nas ciências sociais, porém, tem-se, na melhor das hipóteses, uma confrontação entre diversas teorias não comprováveis. Na maior parte das vezes, não há nem mesmo uma confrontação, mas, sim, uma cuidadosa recusa recíproca, uma desatenção de todos os lados, o que é relativamente fácil, devido ao tamanho das comunidades científicas, divididas em escolas. Isso é verdadeiro para todos os países, grandes ou pequenos (Mattei Dogan, 1966).

\footnotetext{
1 Postura crítica evidente, em particular nos destaques que a maioria dos pesquisadores fez das inquietudes sociais importantes na região, nos temas colocados para a reflexão, e nos problemas particulares priorizados para estudar nos anos que vêm. O XX Congresso da ALAS foi realizado no México em outubro de 1995. Oliver Costilla, 1996; Sosa Elízaga, 1996.
} 
O que poderia ser, então, um avanço da teoria social no pensamento crítico da América Latina? Quais poderiam ser as suas linhas de abordagem? Mencionei em trabalho anterior (Oliver Costilla, 1996) que um primeiro grande desafio da produção teórica caminha pela superação do imediatismo nas ciências sociais. Agora, desejo colocar mais outros elementos.

\section{A luta contra o empirismo}

Uma das manifestações do empirismo na sociologia foi o aparecimento mundial de uma multiplicidade de abordagens e temáticas especializadas de estudo social auto-referido, sem nenhuma relação com a totalidade social e com a sua dinâmica:

De 1970 em diante, o crescimento começou a ocorrer junto com um processo de fragmentação, com o resultado de ser a sociologia, hoje, nas democracias desenvolvidas, uma disciplina heterogênea e centrífuga. Dependendo da maneira como ela é definida, pode-se falar de 35 a 40 sociologias setoriais, indo em todas as direções: para a história, a economia, a política, o direito, a vida social, a indústria e a religião. Não há atividade social que não tenha seu sociólogo oficial, como a sociologia da educação, da família, da criminalidade, das comunicações, do lazer, da terceira idade, da medicina, das organizações - a lista é longa (Mattei Dogan, 1996, p. 105).

A construção de um horizonte explicativo para os problemas e fenômenos captando a sua dinâmica essencial e construindo categorias e relações explicativas deveria constituir parte obrigatória da nova reflexão social. A meu ver, o desenvolvimento desta reflexão exige o estabelecimento das 
relações dos fenômenos particulares com a totalidade social, resgatando, de forma crítica e ampliada o legado crítico anterior. Em fim, constituição de um horizonte explicativo, resgate da dinâmica essencial, construção de categorias e relações, estabelecimento da vinculação com o todo, como uma tentativa para superar definitivamente o predomínio do empirismo na época da globalização (Bagú, 1996). Tal empirismo nada mais é que a adaptação pura e simples do pensamento ao capitalismo existente e dominante globalmente.

As inovações do pensamento social do último decênio, fortemente presentes nas pesquisas criativas da América Latina, colocam perspectivas muito atraentes para analisar aspectos da realidade, antes ignorados. $\mathrm{O}$ imaginário nas organizações sociais, as identidades como referência dos grupos sociais e dos indivíduos, os aspectos simbólicos do poder, a revalorização da experiência no comportamento dos indivíduos, o papel da linguagem e dos significados nas relações sociais. No entanto, todos estes novos enfoques de pesquisa, junto à rejeição dos "enfoques tradicionais" dos clássicos, têm levado muitos estudos a entender o mundo como uma realidade fragmentada. Nesta perspectiva, o mundo hoje se apresenta como uma entidade parcializada, na qual a economia não tem relação com a sociedade, nem esta com a política ou com a cultura, etc. A sociedade, nestes enfoques, é inapreensivel como totalidade. A própria idéia de totalidade não tem guarida teórica nenhuma. Então, a sociologia inovadora tem, de fato, feito o que afirma o ditado popular: "um passo adiante, dois passos atrás". Eis um problema teórico: a separação da realidade em mundos fragmentados, desconexos.

Voltar a incluir o enfoque da totalidade na análise social não quer dizer entender o mundo como se fazia há vinte anos atrás, ou seja: como uma realidade linearmente articulada entre economia capitalista, classes sociais tradicionais, luta pelo poder político com interesses bem definidos, 
ideologia alienada, etc. A historia tem mostrado que o mundo tem manifestações próprias, em movimento constante, que as classes sociais que existem na produção, podem expressar posições ou opções políticas complexas e muito diferentes das que linearmente expressariam seus interesses e que a política e a ideologia têm mediações próprias. Logo, totalidade não quer dizer, então, repetição das articulações do passado. A cultura tem uma relação intrínseca com a sociedade, com a política e com a economia. E o papel da teoria é desvendar a relação entre os fenômenos e tentar descobrir sua real vinculação e respectivas mediações.

A legítima abertura da sociologia dos anos noventa a novos enfoques e novos objetos de estudo, em muitos casos, tem levado a deixar de lado uma das mais importantes heranças da história sociológica: o estudo e a classificação das estruturas, dos processos, dos atores e das instituições sociais. E mais: secundariza dois elementos essenciais e consagrados na compreensão sociológica da dinâmica social: 1) a análise das tendências no desenvolvimento social e 2) a analise da influência das classes e dos grupos sociais na conformação das instituições, na determinação do poder e do domínio e na elaboração das identidades e das utopias. A teoria tem que insistir em recuperar este aspecto da sociologia para mostrar a dimensão histórico-social dos fenômenos que estuda. Sem essa dimensão histórico-social, os objetos de estudo ficam como que isolados numa "torre de cristal", como uma manifestação erudita que não diz nada para o avanço do conhecimento social.

Outra manifestação do predomínio do empirismo na sociologia foi o deslizamento contínuo dos pesquisadores de uma teoria para outra, sem debate e sem balanços que dessem conta da sua inadequação para o estudo dos fenômenos. Nos anos oitenta, foi-se popularizando o ecletismo teórico, vertente que, na verdade, utilizava a mistura das teorias para fugir 
do pensamento teórico e de suas regras:

A assunção de diferentes posturas teóricas em sociologia não tem levado sempre a saldar contas, fazer balanços, senão a um deslizamento conceptual... Depois de meados de 1980, a pesquisa empírica de uma variedade de objetos foi muito abundante, junto com a pouca profundidade no debate teórico. Aparentemente, o que tem guiado os pesquisadores é sobretudo um critério prático e plural na definição de seus instrumentos conceptuais. Dita prescindencia com respeito à dimensão teórica tem a ver com o modo de funcionar normalmente a nossa disciplina (Lídia Girola, 1996).

Só depois de duas décadas, em meados dos anos noventa, a trajetória das ciências sociais parece voltar-se para o trabalho teórico, tanto na América Latina como no mundo todo, agora carregada de um abundante conhecimento empírico:

Na medida em que amadurece e espalha antenas em todas as direções, a sociologia torna-se consciente da sua excessiva fragmentação e dispersão e experimenta a necessidade de retornar a seu centro - não sendo porém bem-sucedida, até o momento. Este processo é assim descrito por Ralph Turner: A sociologia passou de uma fase de ênfase na teoria, com poucas bases empíricas testáveis, para outra de empirismo antiteoricista, e daí para uma outra fase, na qual a pesquisa é vista primordialmente em função de sua relevância para a grande teoria (Mattei Dogan, 1996, p. 106). ${ }^{2}$

\footnotetext{
2 Na verdade, nem tudo é tão unilateral e simples assim. Dos anos vinte aos anos setenta, o pensamento social crítico latinoamericano, com ênfase na teoria, também atendeu à pesquisa empírica. De fato, muitos estudos clássicos que acompanham suas análises com pesquisas empíricas, vêm dessas datas. São de autores como Ramiro Guerra, Silvio Frondizi, Caio Prado jr., Sergio Bagú, José Revueltas, Gino Germani, Julio César Jobet, Euclides da Cunha, Pablo González Casanova, Ruy Mauro Marini, René Zavaleta, dentre outros (Millán e Marini, 1995).
} 
Assim, abre-se espaço para uma saudável tendência nas ciências sociais: superar o empirismo reencontrando-se com a teoria. A própria postura contestatória ante o neoliberalismo já é um bom indicador. Além do reconhecimento do horizonte teórico como necessário para entender as sociedades de finais de século, cabem as perguntas: Quais são as perspectivas, opções, linhas, processos e abordagens do trabalho teórico na atual fase de crescente encontro entre a pesquisa e a grande teoria? Como pode a teoria social crítica latino-americana desenvolver-se criativamente? Quais são os principais obstáculos para isso?

\section{A crise da civilização}

Uma necessidade fundante, hoje, para a América Latina é atualizar a sua procura de desenvolvimento: como estar à altura do mundo, como universalizar-se para viver o momento histórico atual com todas as potencialidades sociais possíveis, superando formas de produção e de vida atrasadas e caducas. E mais: como co-participar na crítica das novas formas modernas e pós-modernas, vislumbrando novos modelos de civilização.

A exigência principal colocada para as ciências sociais da nossa região reedita, com novas formas, um velho dilema já posto nos anos cinqüenta: explicar e criticar nosso atraso latino-americano. No entanto, esta exigência não pode, em nenhuma hipótese conduzir-nos a tomar como referência o espelho neoliberal do capitalismo mundial. O objetivo de nosso desenvolvimento não pode ser o de ocidentalizarmo-nos à maneira norte-americana ou européia, com o seu individualismo egoísta, sua exploração industrial e cibernética, sua violência social, sua alienação e sua máquina de guerra e ódio nacional e social. Antes de tudo é preciso fazer a crítica do atraso, junto com a critica da modernidade da qual este atraso faz parte, impedindo o nosso desenvolvimento, pela dependência e pela 
subordinação. A crítica tem que demonstrar o "porquê" da crise do EstadoNação e as causas da existência de uma sociedade de exploração irracional dos homens e da natureza, marcada por uma nova exclusão social e uma falta de valores humanistas aliadas a uma concentração de riqueza e poder anormais nos países de capitalismo avançado, e em nossos próprios países.

Os aportes que a América Latina pode dar à crítica e à renovação da democracia política, à reforma da produção e da vida, ao humanismo e ao comunitarismo radical renovado, têm que se encontrar com os velhos objetivos de libertação nacional e social do mundo atual, adaptados às novas condições. De fato, nem libertação nacional nem libertação social podem ser configuradas como no passado. Não estamos buscando, no Ocidente, o que as suas sociedades avançadas são hoje. Pelo contrario, estamos junto ao Ocidente, lutando por um mundo distinto. Nossa definitiva ocidentalização, então, vai consolidar-se quando a América Latina aportar novas opções para o mundo contemporâneo.

É mister aceitar que o pensamento social ocidental dominante até hoje tem sido e é, em muitos aspectos, simplista e excludente. A velha fórmula de que A não é B e faz exclusão de B resulta, evidentemente, falsa. Para entender o mundo atual, e especialmente para compreender a América Latina, hoje, é imprescindível abrirmo-nos à compreensão de que $A$ inclui B e o pressupõe, implica-o. Assim, o refinamento institucional e a luta civilizada e regulamentada da política nos estados e nas grandes metrópoles da região assentam-se, normalmente, na opressão brutal e na violência no campo e no mundo do trabalho e até mesmo as pressupõe.

A riqueza, o desenvolvimento tecnológico e científico e a educação dos países avançados têm como base a superexploração dos recursos naturais e do trabalho social, tanto nas regiões e países periféricos como nas áreas terceirizadas dos próprios países de capitalismo avançado. A mesma coisa pode dizer-se das megacidades, que são núcleos extraordinários de desenvolvimento industrial, comercial e de serviços, cujo fundamento é a migração rural proveniente de um campo empobrecido e sem recursos, que, na verdade, ficou pobre por ter financiado, durante décadas, o desenvolvimento industrial das cidades. 
Os problemas sociais não têm existência isolada. Para caracterizá-los, realmente, é necessário estabelecer os vínculos entre cada fenômeno e todos os aspectos da dinâmica social. Somente depois de tal vinculação teremos uma visão total e complexa do conteúdo dos ditos fenômenos que articuladamente constituem a questão social de uma dada sociedade. Logo, fenômenos como, por exemplo, a acumulação de capital (tão bemvista pela sociedade na sua forma de crescimento do produto interno bruto anual) é a outra face da exploração do trabalho social ou, também, o desenvolvimento tecnológico é a outra cara da exclusão social de milhões de desempregados permanentes e de meninos sem escola nem trabalho, etc.. Ou ainda, a incerteza e a pobreza de milhões de latino-americanos são a outra face da geração de novos-ricos na região, como o registra periodicamente a revista norte-americana "Forbes". É preciso sempre ter presente que a realidade é multilateral, e o pensamento não pode ser outra coisa que isso: interdisciplinar e multilateral.

A reflexão teórica sempre tem uma referência histórica e cultural que ilumina o sentido profundo das coisas. Trata-se de um horizonte de conhecimento da época, do tempo vivido e da cultura socializada. A teorização dos problemas, hoje, tem que considerar que já vivemos os problemas do século XXI. O nosso horizonte está marcado por fenômenos específicos: a queda do socialismo real e o descrédito das utopias, a mundialização do capital, a reestruturação produtiva, a transformação do trabalho, o desemprego estrutural, a globalização tecnológica e comunicacional; o enfraquecimento da soberania nacional e da responsabilidade social dos estados; a marginalização crescente de muitos países subdesenvolvidos, numa palavra, o nosso horizonte está marcado pela crise das civilizações modernas que, no século XX, procuraram respostas ao desenvolvimento humano.

Uma nova "visão do mundo" tem que acompanhar a teoria latinoamericana do século XXI. Esse horizonte inclui a crise cultural-civilizatória das construções histórico-sociais que formaram o mundo nos últimos dois séculos, tanto capitalistas quanto socialistas. Esta consideração essencial tem 
sido feita, não por acaso, no balanço da situação do mundo nos fins do século XX por quatro dos maiores filósofos e historiadores das ciências sociais: Sérgio Bagú, Adolfo Sánchez Vázquez, Erich Hobsbawm e Immanuel Wallerstein (textos de 1995 e 1996).

A noção de crise da civilização é muito abrangente, incluindo as relações de produção e de troca, as formas sociais, as instituições, as organizações e as relações políticas e culturais, as identidades, o imaginário, os projetos de hegemonia, as ideologias e as utopias, enfim, têm a ver com as produções histórico-sociais dos homens ao longo destes dois séculos que não contemplam uma real dimensão humanista.

A nossa época vive uma encruzilhada: como toda crise, a atual é o momento mais propício para profundas frustrações e para grandes mudanças, para um questionamento global e para um desenvolvimento político-ideológico de grandes proporções. A crise cultural de hoje, como as crises similares do passado, propicia grande criatividade teórica e evidencia um grande potencial político.

A consciência da crise de civilização que vivemos deve permear o pensamento teórico contemporâneo das ciências sociais: a teoria não é a mesma quando leva em consideração este ponto de partida. Como diziam os clássicos da filosofia (Kant, Hegel), a crise é o lado negativo do qual temos que partir para a nossa construção teórico-conceitual; é o caminho para enxergar as novas possibilidades. Aliás, isso afeta nosso olhar diante de qualquer fenômeno ou problema social.

A consciência da crise de civilização pode mudar nossa apreciação das alternativas críticas ao capitalismo transnacionalizado. Por isso, não é suficiente questionar as soluções erradas, experimentadas pelos regimes comunistas autoritários e burocráticos do século XX, e defender que o verdadeiro comunismo ou o socialismo clássicos ainda são a alternativa ao capitalismo contemporâneo. Precisa-se, sim, redefinir a concepção e os projetos socialistas e comunistas a partir de uma critica radical às experiências e às teorizações 
do comunismo do século XX, concebendo-as como tentativa civilizatória que fracassou. E mais: essa redefinição de projetos precisa considerar o cenário das transformações do capitalismo mundializado, no sentido de buscar alternativas e saídas que recuperem, nas novas condições hoje postas, o poder do trabalho sobre o capital.

A nova perspectiva leva a mudar, inclusive, a visão que o pensamento crítico latino-americano tem do pós-modernismo como uma teorização niilista que se baseia no estado de ânimo. De fato, se deixarmos de lado as teses do relativismo total, uma concepção do pós-modernismo pode estar falando desta mesma crise:

Essa idéia de modernidade aponta para o pós-modernismo e a pós-modernidade, sendo que esta última não deve ser entendida como uma nova época que agora substitui a idade moderna, mas como a consciência crescente dos limites do projeto de modernidade. É claro que há muitos problemas, na tentativa de produzir definições para pós-modernismo e pósmodernidade. Simplificando, pós-modernismo sugere o problema de lidar com a complexidade cultural, de lidar com aquilo que, do ponto de vista de categorias bem organizadas, parece ser desordem, mas que não pode ser adequadamente incorporado na classificação existente nem ignorado. É possível identificar algumas características. Em primeiro lugar, pós-modernismo implica uma perda de confiança nas grandes narrativas de progresso e iluminismo, centrais à modernidade ocidental. A confiança na universalidade desse projeto é substituída pela ênfase na contingência, na incoerência e na ambivalência. Há uma consciência crescente da multicodificação, da hibridização e do sincretismo cultural. Em segundo lugar, tem havido democratização e popularização de formas de conhecimento e de produção e difusão cultural que eram previamente 
monopolizadas ou controladas por grupos estabelecidos (Mike Featherston, 1996).

Com a recuperação do horizonte da crise civilizatória da nossa época, a teoria ganha também, porque o processo de pensar transforma-se numa exigência radical de hoje para todos nós.

\section{A globalização e as novas perspectivas analíticas}

Um fenômeno tão abrangente e tão radical como a globalização, de qualquer maneira que esta seja entendida, não pode ser assimilado como a ideologia neoliberal impõe: como se o fenômeno fosse único, seguindo o mesmo processo em todo o mundo. A sociologia latino-americana ajuda para compreender que a globalização é um fenômeno qualitativamente diferente nos países centrais e nos países de capitalismo dependente na América Latina. Em verdade, em nossos países, a globalização é uma redução do tempo e do espaço à condição de que participemos como regiões subordinadas dentro de um plano estratégico mundial.

A globalização significa coisas diferentes para o grande capital transnacionalizado, para os trabalhadores, para a pequena e média indústria, para quem pode concentrar a renda nacional e para quem passa a ser excluído permanentemente pela redução do emprego ou pela falência da produção.

O capitalismo do nosso fim de século está mudando demais, expandindo suas potencialidades de assimilação mundial e subordinando os processos sociais de caráter local, alicerçado numa extrema mobilidade. Sem dúvida, a teorização dos fenômenos sociais, quaisquer que sejam eles, tem que estabelecer a sua relação com a reestruturação do capitalismo mundial, com a globalização. De fato, há, ainda, o ressurgimento do local, que pode ser observado em muitos acontecimentos importantes do nosso tempo na América Latina. Esse ressurgimento faz parte das resistên- 
cias e das novas possibilidades geradas pela mundialização do capital: a insurreição indígena zapatista no México; a modernização industrial do nordeste no Brasil; os pactos bilíngües e biculturais "indios-ladinos" no poder na Bolívia; as novas manifestações do sincretismo religioso e cultural em Cuba; o avanço para um Estado multinacional na Guatemala, etc.

Evidentemente a crítica latino-americana precisa considerar o horizonte da mundialização do capital para estudar o novo sentido dos fenômenos sociais, sejam estes fenômenos sociais globais, grupais ou individuais. Tudo tem que ser analisado a partir desta perspectiva: os processos produtivos, o trabalho, o emprego, a acumulação; os problemas das grandes cidades e das pequenas vilas; as migrações; as relações políticas e os processos eleitorais; o neoliberalismo, as políticas sociais, o papel das minorias, a situação do meio ambiente, a violência intrafamiliar, do estatal e outros.

Mas, o que é a globalização, além da visão plena de ideologia que os meios de comunicação e o discurso do poder nos apresentam todos os dias? Qual globalização vamos utilizar como horizonte de conhecimento do social? Aquela que exige uma adaptação maior ao capitalismo mundial, tal como ele é hoje, ou aquela que nos abre novos horizontes para conhecer e criticar o mundo?

Compete à teoria acompanhar as experiências da sociedade no novo fenômeno da mundialização, para encontrar alternativas às políticas neoliberais. Para isso, temos que adentrar com profundidade no estudo do processo de reestruturação do capitalismo mundial. ${ }^{3}$

\footnotetext{
3 Num outro trabalho, estudo alguns aspectos da globalização e da mundialização do capital (A globalização e a nova crítica do Estado latino-americano, Lúcio Oliver Costilla, 1997), e tento colocar alguns argumentos para distinguir as diversas concepções que sobre ela se tem nas ciências sociais atuais.
} 
A globalização é um fenômeno condicionante dos processos sociais e é também um novo cenário espaço-temporal para o desenvolvimento ou, ao contrário, para o desmantelamento de velhas classes, grupos sociais, instituições, organizações e indivíduos. A teoria precisa entender o alcance do referido condicionamento.

Na medida em que a produção e o mercado já não estão isolados no âmbito nacional, em que tudo faz parte da concorrência mundial, em que as comunicações e as tecnologias unificam o mundo e abrem as portas para uma reorganização econômica, política e cultural mundial, a perspectiva da globalização está gerando muitos e diversos conceitos analíticos: mundialização do valor, novo papel social do trabalho vivo e da ciência, terceirização, análises simbólicas, flexibilidade laboral, reestruturação produtiva, desestatização e desnacionalização do Estado, nova exclusão social, novo comunitarismo, partidos-movimentos, globalismo e universalismo, homogeneização, localismo, particularismo, fragmentação, masculinidade, países integrados, regiões inseridas, países e grupos sociais excluídos, desemprego estrutural, dentre tantos outros que permeiam os discursos acadêmicos e políticos e a própria mídia.

Todos são novos conceitos, plenos de conteúdos e ainda pouco trabalhados. Alguns deles, como, por exemplo, o papel do trabalho vivo na produção e o papel da ciência, têm conseqüências fundamentais para a compreensão da própria acumulação do capital e para a constituição das classes sociais no século XXI.

A caracterização das mudanças tem que levar a uma nova produção teórica, a outros horizontes e conceitos, a novas determinações e indeterminações, outras contradições e relações e a novas explanações. A questão não é somente usar "conceitos da moda" e utilizá-los na pesquisa, mas, sim, estabelecer o vínculo do que é particular e concreto com os processos gerais e os fenômenos abstratos. 
É inegável que, atualmente, a teoria tem que lidar com o problema, pois falar hoje de globalização, é uma referência obrigatória nas ciências sociais dominantes:

O processo de globalização parece ser assunto obrigatório hoje em todo tipo de publicação ou debate. Por mais que a palavra venha se desgastando, a realidade socioeconômica e cultural deste processo não pode ser eludida por cientistas sociais interessados em compreender tanto a natureza das novas formas de produção e consumo quanto as caraterísticas dos agentes envolvidos (Editorial. Sociedade e Estado, vol. XI, n. 1, janeiro-junho 1996. Departamento de Sociologia da Universidade de Brasília, p. 5).

A imagem da globalização projetada pelos grandes meios de comunicação de massas é um sonho romântico, que fala de uma modernização radical das economias de todos os países, do acesso generalizado a novas formas de produção, da capacidade que todo mundo tem de adquirir novos objetos de consumo no mercado, da nova informação e intercomunicação mundial. Nesta perspectiva global, os homens viram universais na sua relação social, tudo "sob a sombra aconchegante dos valores absolutos e eternos da liberdade de mercado e do Estado político, democrático e liberal".

Esta imagem intencionalmente trabalhada da globalização é a unilateralização "boa" de um fenômeno que tem muitas contradições. De fato, a crítica do fenômeno tem demonstrado que a globalização põe em cima da mesa a dominação mundial de uma nova classe industrial e financeira, a exclusão social de amplos setores de pobres e desempregados, a marginalização nacional da maioria dos países subdesenvolvidos, a subordinação do mundo ao poder político, financeiro e militar dos Estados Unidos, a extensão da irracionalidade na exploração da natureza pelos interesses industriais e uma maior alienação dos homens ao consumo sun- 
tuoso (Santos, Milton, 1993; Santos, 1995).

A globalização, do ponto de vista mais rigoroso, é uma nova forma de organização da economia mundial. É a mundialização do capital:

Trata-se de um dado estágio de desenvolvimento do capitalismo, que se caracteriza por um aprofundamento da concentração do capital e de uma nova forma de organização das empresas, pela financeirização e pela fragmentação... é antes de tudo um processo que ocorre no plano da organização industrial, como resposta defensiva das empresas multinacionais ao fim da onda larga de expansão capitalista ocorrida no inicio dos anos 70 (Rosa Ma. Marques, 1996).

A nova forma de produção e de gestão mundializada, a internacionalização das relações de produção capitalistas, a expansão mundial dos mercados, a reorganização administrativa global, a reestruturação produtiva, a flexibilização laboral, o próprio predomínio do capital industrial e financeiro não são somente questões técnico-econômicas: são uma nova capacidade de poder, de domínio, na relação do capital em todos os âmbitos. Configuram um novo poder no mundo, concêntrico em grandes oligopólios (Chesnais, 1994), embora tenham um alto grau de fragmentação e concorrência entre eles. Em verdade, os oligopólios desenvolvem sua hegemonia através dos Estados nacionais dos países industrialmente desenvolvidos, sedes desses oligopólios, e dos Estados nacionais "reformados", fragmentados e enfraquecidos dos países subdesenvolvidos e ainda, por meio dos organismos financeiros transnacionais.

A forte influência da economia e da política na vida social, não significa que o fenômeno da globalização fique reduzido à economia e à política. No âmbito sociocultural e das comunicações, a globalização tem uma dinâmica própria que acompanha e reproduz o fenômeno de uma forma geral. A cultura tem suas próprias dinâmicas, que, uma vez iniciadas, podem conduzir para rotas singulares inimagináveis, influindo na própria re- 
produção política e econômico-social. Assim também no âmbito da cultura, é necessário um enfoque complexo da globalização, que inclui o local como espaço de redefinição da tendência homogeneizante:

O que parece claro, é que não se trata de considerar o global e o local como dicotomia separada no espaço ou no tempo, e sim que os processos de globalização e localização são indissociáveis na fase atual (Featherstone, 1996, p. 11).

Cabe então uma questão chave: como fica a América Latina ante os processos de globalização, de mundialização do capital? A América Latina encontrou-se com a globalização através das políticas neoliberais de ajuste e reforma do Estado, determinadas pelos Estados Unidos, Alemanha e Japão, e via a pressão econômica e ideológica das instituições econômicofinanceiras multinacionais Banco Mundial, Fundo Monetário Internacional, Banco Interamericano de Desenvolvimento. Concretamente isso se vem dando através do ingresso intensivo dos investimentos externos diretos e das corporações transnacionais, com a devida concordância e cumplicidade das novas elites econômicas e políticas latino-americanas.

A mundialização do capital revestiu-se de neoliberalismo, constituindo a ideologia da globalização. Isso gerou, nos movimentos populares, uma visão unilateral de rejeição, voltando-se, muitos destes, para projetos estatistas nacionalistas do passado (neovarguismo, neocardenismo, neoperonismo), que não são alternativas reais ao novo fenômeno, porque o capitalismo atual não pode dinamizar-se através apenas de mercados e Estados nacionais.

Hoje sabemos que o neoliberalismo é o caminho antipopular e autoritário da mundialização, um caminho que lembra muito as velhas revoluções cupulares realizadas pelas elites burocráticas, consolidadas no aparato estatal. Elas usam o Estado para destruir o poder econômico e político de uma fração capitalista já superada pelas novas relações mundiais do capital, 
impondo então, uma nova dominação burocrática e transnacionalizada, que exclui a presença e a participação de grandes massas populares.

Mas a mundialização é um fenômeno que, teoricamente, pode desenvolver-se por outras vias, inclusive até progressistas, com a participação dos trabalhadores. Já temos algumas experiências que mostram que as possibilidades existem e que poderiam ser reais com outras correlações de forças. Uma delas é o acordo das montadoras entre trabalhadores e empresas transnacionais de automóveis no Brasil, em 1993 (Oliveira, 1993), quando o sindicato participou da reestruturação produtiva, melhorando a produção, mantendo o emprego e aumentando salários. Este exemplo ainda é excepcional num mundo em que a inserção dos países da América Latina na mundialização se faz a partir da quebra dos direitos dos trabaIhadores, da super-exploração da mão-de-obra e dos subsídios estatais. O posicionamento capitalista dos Estados, via sua transformação em Estados nacionais de competição (Hirsch, 1996) na América Latina, não tem levado a um verdadeiro posicionamente, mas à sua subordinação servil aos grupos financeiros. Na América Latina, os Estados são intermediaristas, ajustadores, de gerenciamento do capital financeiro.

$\mathrm{Na}$ América Latina, o Estado nacional vem sendo reformado para se adaptar à mundialização do capital. São as chamadas reformas do Estado, definidas na agenda estratégica do "Consenso de Washington", as quais viabilizam a inserção subordinada e fragmentada dos países. Numa outra perspectiva de inserção na mundialização, o Estado nacional precisa ser reformado, integrando a sociedade. Assim, a reforma do Estado teria que ser sobretudo política, para que o novo Estado e as economias regionais pudessem inserir-se como totalidade e não em pólos particulares. Em termos concretos, tal reforma teria que conceber a mundialização como a grande oportunidade para desenvolver um novo projeto de desenvolvimento nacional e popular para modernizar as pequenas e médias indústrias, para transformar o campo, para resolver os problemas de saúde, educação, 
emprego. Enfim, para incorporar a sociedade num grande plano de desenvolvimento em que os trabalhadores ocupem de novo espaços próprios de poder autônomo.

A reforma do Estado feita não tem a ver com as verdadeiras necessidades dos países da América Latina; foi, simplesmente, a reestruturação da burocracia, a privatização e a inserção subordinadas ao poder do grande capital financeiro e industrial transnacional.

\section{Por uma nova democracia: sem exclusões, nem excluídos}

Depois de duas décadas, pode-se constatar que o retorno à democracia em grande parte dos países latino-americanos tem significado afirmar o Estado neoliberal transnacionalizado, acompanhado de processos e práticas da democracia política. Tem havido, certamente, um desenvolvimento do jogo político aberto, da representatividade e da cultura política cidadãs, junto a um agravamento da pobreza, do desemprego e da exclusão sociais.

Este fenômeno tem levado uma parte da intelectualidade a desiludir-se com o desenvolvimento democrático, o que coloca em discussão a questão da legitimidade de um Estado que se orienta pela governabilidade, mas não resolve problemas sociais urgentes. Em geral, o que prevalece são as políticas neoliberais do Consenso de Washington. Nessas políticas, o principal tem sido a transferência de recursos do Estado para o capital privado, com a idéia de apoiar a formação de supostos novos empresários, capazes de reconstruir o capitalismo para participar na globalização. Três mecanismos têm sido os principais na agilização dessas políticas: o ingresso dos investimentos estrangeiros diretos; a privatização das empresas estatais e o apoio a um acelerado processo de concentração e centralização de 
capital transnacionalizado (Fiori, 1997).

São poucos os casos latino-americanos em que a cidadania está realmente vinculada ao enfrentamento da questão social. Os Estados têm reduzido as suas políticas públicas, privilegiando o pagamento dos serviços das dívidas externa e interna. O orçamento dedicado às políticas sociais representa um percentual muito baixo do gasto público.

O que é então a democracia nas nossas sociedades latino-americanas, especialmente hoje que está representada como o objetivo máximo a obter? O que significa a existência de um povo nacional, cujas maiorias vivem na exclusão social e na marginalidade, embora façam parte do desenvolvimento da democracia?

Para refletir sobre estas questões, convém demarcar duas considerações: primeiro, a democracia não resolve, por si mesma, a questão social. A democracia faz parte do âmbito do político, da organização do poder, do Estado político na forma republicana, baseando-se na separação entre a esfera do político e a esfera do social. Os assuntos relacionados à condição social - o trabalho, o emprego, o salário, a moradia - na visão formal e estreita do Estado político, fazem parte do privado social. ${ }^{4}$

Nesta perspectiva analítica, os ideólogos do Estado liberal, fundados na teoria da separação entre o âmbito político e o âmbito privado, afirmam ter colocado as coisas em seu devido lugar. Assim, a democracia no âmbito liberal, assume uma dimensão restrita, efetivando-se sem colocar em pauta os reais interesses públicos, configurados nas questões decorrentes do próprio movimento do capitalismo contemporâneo: concentração de renda, desemprego massivo, precarização das relações de trabaIho, exclusão social, entre outras.

4 Constitui exceção uma forma específica de Estado funcional a um determinado momento de acumulação do capital - o chamado Estado de Bem-Estar - no qual se tem uma intervenção efetiva na questão social. 
Para salvaguardar os seus interesses ante o desenvolvimento democrático, o bloco de poder dominante, composto pelas elites econômicas e políticas do capitalismo transnacionalizante, tem optado por sacralizar a relativa separação entre o âmbito político-parlamentar e o âmbito do Poder Executivo no tocante à política econômica nacional e local. Nas instâncias legislativas, não se discute seriamente os problemas referentes à política econômica, nem aqueles que têm a ver com o uso do orçamento do Poder Executivo. Tem-se utilizado a separação entre o Poder Legislativo e o Poder Executivo para diminuir os espaços públicos e cooptar os partidos e os parlamentares, alem de excluí-los de determinados assuntos públicos de importância fundamental. Isso tem definido, ainda mais, a tendência moderna de que o poder real (quem tem nas mãos as decisões) fique concentrado no Executivo, deixando para os poderes Legislativo e Judiciário tarefas secundárias de fiscalização.

Em princípio, a democracia como forma política de constituição do poder público, constitui um espaço aberto para que a luta social defina a orientação do poder. No entanto, no cenário latino-americano contemporâneo, a expressão pública da hegemonia capitalista, a nova tecnocracia moderna especializada, quase sempre controla a vida política, tanto dentro como fora das próprias instituições. Quem ganha na democracia é quem tem os aparelhos de poder, quem tem o domínio do conhecimento especializado nas mãos. Neste contexto, a conquista da democracia republicana não exime os trabalhadores de construírem uma hegemonia própria, hegemonia que implica uma outra visão de mundo e construção de políticas distintas para o enfrentamento da questão social. Mas a consecução da democracia, o desenvolvimento da cidadania política, a existência de plenos direitos políticos não significam necessariamente o triunfo de uma cultura política dos trabalhadores nem a sua real participação nos assuntos do Estado. Pode significar o êxito de uma visão empresarial privada nos assuntos sociais. Por isso, a democracia não pode ser somente um 
objetivo. Tem também que ser o espaço em que se confrontam opções hegemônicas diversas, no qual os trabalhadores desenvolvam seu próprio perfil de políticas nacionais, estaduais e locais.

O Estado nacional tende à obsolescência? Hoje o fim do Estado Nação é um argumento muito corrente em nossos tempos e está carregado de reducionismo econômico e de ideologia. A globalização do capital, dos mercados, da produção econômica mundial, está realmente transgredindo os limites estatais e nacionais. Porém, concomitantemente a estes processos econômicos, somente na Europa Ocidental existe um processo político de criação democrática com tendência a um Estado regional, a União Européia.

Na América, não existe nada similar, e falar da obsolescência do Estado-Nação só serve para legitimar as políticas de um proto-Estado americano regional (isto é, um Estado autoritário em processo), constituído pelo governo dos Estados Unidos, por organismos empresariais transnacionais - como o Conselho das Américas - e por organismos financeiros multinacionais - o Fundo Monetário Internacional e o Banco Mundial. Esse proto-Estado transnacional norte-americano não expressa a construção democrática de um Estado político regional que substitua o EstadoNação na América Latina, e, sim, revela a imposição autoritária de uma política econômica em benefício do grande capital transnacional norteamericano. Em vista disso, o Estado-Nação latino-americano - como expressão da vontade de soberania política e nacional dos povos - segue vigente, como o faz há duzentos anos, apesar das tendências contemporâneas da mundialização do capital.

Hoje a nação precisa ser uma formação social aberta, em movimento e reorganização, na qual seus membros tenham outros direitos além da cidadania política. Esta "nação popular" será uma resultante da luta pelo aprofundamento da democracia, buscando obter espaço para grandes mudanças. Em verdade, é a busca de um espaço político no qual possam surgir 
e se desenvolver forças sociais, políticas e culturais nacionais com capacidade para o confronto com a atual hegemonia capitalista autoritária. A nova sociedade civil terá que reconhecer as suas diversas fisionomias e entender a necessidade de organização e luta para se manter viva. Sem dúvida, a internacionalização do capital e dos mercados aponta a tendência de que a Nação fique somente como uma mensagem cultural prescindível, como um "folclore de fim-de-semana", embora as novas conceituações sobre o nacional permitam associar a Nação com a expressão plena do particular em termos universais.

Para que os conceitos políticos e sociais não sejam utilizados em um sentido empirista ou imediatista e para aprofundar o horizonte de conhecimentos e o processo histórico pertinente, temos que encontrar o universo de referência. Podemos tentar entender isso melhor com a análise de uma das questões mais vitais da polêmica sociológica e da luta política hoje em dia: uma democracia sem exclusões e sem excluídos.

Depois do retorno democrático no sul da América Latina, do triunfo do neoliberalismo, da reforma dos Estados e da queda do socialismo real autoritário, ficou o caminho aberto para a construção de um consenso de que o melhor sistema de poder, no mundo moderno, são as repúblicas ou as monarquias constitucionais democráticas. A democracia é, hoje, a forma política com maior legitimação. À procura da governabilidade, periodicamente se prometem avanços substanciais pela via que conduz a uma maior democracia no futuro. Daí, que a grande tarefa dos nossos dias seja a consolidação e o aprimoramento da democracia. Mas qual democracia tem que se consolidar e aprimorar? Para que serve a democracia do ponto de vista dos interesses das grandes maiorias, dos excluídos?

Hoje é consensual que a democracia é um conjunto de determinadas regras do jogo político institucional para "uma boa sociedade": 
...um conjunto de regras 'certas' do jogo que permita institucionalizar e provisoriamente resolver os antagonismo sociais e chegar a resultados 'incertos', isto é, nem sempre necessariamente favoráveis aos interesses das classes dominantes; por outro, a democracia também contem uma definição da 'boa sociedade' (Borón, 1994, p. 13).

Na América Latina, o retorno à democracia gerou um sentido de liberdade política, de participação e vivência de direitos de cidadania, que a região não tinha conhecido nunca, embora a situação social do povo não tenha efetivamente mudado:

...os alentadores avanços políticos registrados nos anos 80 foram acompanhados por uma marcada piora das condições de vida das grandes maiorias nacionais, $O$ que só pode colocar sombras sobre o futuro da democracia nos nossos países (Borón, 1994, p. 12).

Mas, a final o que é a democracia numa sociedade com claros processos de exclusão social? Por que os desempregados, os excluídos, os empobrecidos pelo neoliberalismo, os miseráveis, os cada vez mais numerosos "sem", não fazem uso da democracia para, pelo menos, modificar em algo a sua situação, que parece apresentar-se sem saídas? Ou, ainda pior, fazem uso da democracia e parece que nada dá certo.

Mesmo trabalhando com uma concepção ampla de democracia política, a exigência em aprofundar o conteúdo teórico do conceito é uma necessidade. Para isso, é necessário ir além dos diferentes "temas" da ciência política, relativos à democracia: Estado, soberania popular, representação política, divisão de poderes, Estado de Direito, liberdades sociais e individuais, igualdade. É necessário, mesmo, determinar também qual é a concepção de sociedade e de Estado que se tem no universo intelectual e social do pesquisador (Borón, 1994) e dos problemas que se deseja analisar ou resolver. Só assim, poderemos estabelecer a relação com o fenômeno de exclusão social nos termos contemporâneos. 
Democracia política pode ter um significado diferente, segundo a nossa compreensão da sociedade e do Estado. Se entendemos, como os liberais, que a sociedade é um conjunto de forças sociais, com igual capacidade de poder e influência no Estado, capacidade derivada da sua situação concorrencial no mercado - o problema da democracia política fica reduzido a instituir, manter e consolidar as instituições políticas representativas, baseadas no sufrágio universal, e as regras certas do jogo político. Em síntese, o jogo democrático fica reduzido à luta pela influência e poder entre grupos sociais com interesses distintos e com igual capacidade de conformar maiorias. O Estado somente garante o jogo limpo e o império do direito. E até pode ser um ator a mais entre a multiplicidade de atores que participam no sistema político, sem, com isso, alterar a real concorrência política. De fato, esta é a noção predominante de democracia no Ocidente. E, nesta perspectiva, tudo depende da conformação "livre" de maiorias e minorias em cada uma das questões substanciais. As sociedades latino-americanas já teriam alcançado o objetivo democrático, sem resolver, porém, a exclusão social, mesmo que esta tenha uma história longa nos modelos oligárquicos excludentes do passado e que, hoje, na mundialização de capital, aparece com um caráter estrutural.

O conceito de democracia pode ter outro significado, e os problemas, uma outra dimensão, se entendemos a sociedade em sua natureza capitalista, cuja relação de domínio de classes é determinada pela exploração, acumulação e subordinação, ainda que apareça fantasiada de igualdade política pelas relações de mercado (fetichismo das mercadorias, Marx, O Capital, Tomo I, vol. I). Nessas sociedades, o Estado tem formas históricas particulares de representação do interesse coletivo, de uma instituição legítima, mas também constitui um órgão de poder centralizador, monopólio da força e do direito, mantenedor das relações contratuais de mercado, com um peso decisivo na acumulação. E, assim, a burocracia que o 
conduz não é somente um ator político a mais, mas, sim, a elite condutora que expressa um projeto de sociedade que reproduz uma determinada dominação social. Na maioria das vezes, as mediações políticas giram ou estão centradas no Estado. E mais: o Estado ainda garante e reproduz, no âmbito geral, o domínio da classe capitalista (em nossos dias, da classe capitalista transnacionalizada).

Nesta perspectiva analítica, a democracia política latino-americana não é ainda um espaço de expressão do público, de verdadeira participação política dos segmentos excluídos e, sim, é uma forma da dominação política da nova burguesia transnacionalizada e de governabilidade de um Estado quase mundializado, Estado este sem plena soberania política, sem total soberania nacional e sem uma política de desenvolvimento social. Isto não impede que essa democracia seja também uma forma de luta contra essa dominação política capitalista, um terreno fundamental de organização, desenvolvimento e preparação política das maiorias, de construção potencial de uma nova hegemonia popular, seja através de reformas radicais ou de transformações diversas, para mudar a correlação de forças e a organização produtiva da sociedade e até para propor uma civilização democrática pluralista baseada em novas formas produtivas e econômicas humanistas. Nesta concepção, a democracia existente também é uma via dos excluídos para lutar contra a exclusão social, é um canal dos movimentos sociais para coincidir com partidos políticos críticos da mundialização atual.

Concluímos, com isso, que, para discutir a questão da democracia, hoje, na região da América Latina, ou num dos seus países, temos que desenvolver uma compreensão teórica do problema, como ponto de partida para que a discussão possa aprofundar-se no rumo de corretos resul- 
tados.

Possivelmente, numa discussão política ou num debate popular, não seja importante um aprofundamento das bases teóricas dos conceitos, mas, no âmbito acadêmico, isso é condição fundamental para uma nova produção de conhecimento. Este é mais um dos múltiplos desafios considerados aqui para uma nova sociologia da América Latina.

\section{Referências}

BAGÚ, Sergio. Vivir la realidad y teorizar en Ciências Sociales. Estudios Latinoamericanos, México, CELA-FCPyS, UNAM, Nueva época, n. 4, julio-diciembre. 1995.

BORÓN, Atilio A. Estadolatria e teorias 'estadocêntricas' (notas sobre algumas análises do Estado no capitalismo contemporâneo).In: Estado, Capitalismo e Democracia na América Latina. Trad. Emir Sader. Rio de Janeiro: Ed. Paz e terra, 1994.

COMISSÃO Gulbenkian para a Reestruturação das Ciências Sociais. Para abrir as Ciências Sociais. São Paulo: Cortez Editora, agosto de 1996.

CHESNAIS, François. A mundialização do capital. São Paulo: Xama Ed.,1996.

DOGAN, Mattei. Fragmentação das ciências sociais e recombinação de especialidades em torno da sociologia. Sociedade e Estado, Brasília, vol. XI, n. I, janeirojunho. 1996.

FIORI, José Luís. Ajuste, transição e governabilidade: o enigma brasileiro. In: FIORI, José Luís e TAVARES, Maria da Conceição. Desajuste global e modernização conservadora. São Paulo: Paz e terra, 1994.

FIORI, José Luís. Dança das cadeiras. Revista Carta Capital, 20 de agosto. 1997.

GIROLA, Lídia. 8. Tradiçiones, comunidades disciplinarias y cambios conceptuales. Un brevisimo intento de definición. In: OLIVER COSTILLA, Lúcio (Coord). Balance y perspectivas del pensamiento latino-americano. Cidade do México: Asociación Latinoamericana de Sociología-UNAM-Universidad de Colima, 1996. p. 111. 
HOBSBAWM, Erich. Era dos extremos: o breve século XX, 1914-1991. São Paulo: Companhia das letras, 1995.

MILLÁN, Márgara e MAURO MARINI, Ruy (org). La teoria social latinoamericana. 3 volumens. México: UNAM, 1995.

OLIVEIRA, Francisco de. Quanto melhor, melhor: O acordo das montadoras. Novos Estudos, São Paulo, Cebrap, n. 36, julho. 1993.

OLIVEIRA, Francisco de. Quem tem medo da governabilidade?. Novos Estúdios, São Paulo, Cebrap, n. 41, março. 1995.

OLIVER COSTILLA, Lúcio (Coord). Balance y perspectivas del pensamiento latino-americano. México: Asociación Latinoamericana de Sociología-UNAMUniversidad de Colima, 1996.

OLIVER COSTILLA, Lúcio. A globalização e a nova crítica do Estado latino-americano. Ponencia apresentada ao VIII Encontro Norte/Nordeste de Ciências Sociais. Fortaleza, Ceará, 10-13 de junho de 1997.

SADER, Emir (org). Pós-neoliberalismo: as políticas sociais e o Estado democrático. São Paulo: Paz e terra, 1995.

SÁNCHEZ VÁZQUEZ, Adolfo. Textos sobre democracia, socialismo, esquerda. Dialética, México, Ed. Universidad Autônoma de Puebla, n. 21 a 26. 1992-1996.

SANTOS, Boaventura de Sousa. A construção multicultural da igualdade e da diferença. Mimeo da palestra proferida no VII Congresso Brasileiro de Sociologia, Rio de Janeiro, setembro de 1995.

SOSA ELÍZAGA, Raquel (Coord). América Latina y el Caribe: perspectivas de su reconstrucción. México: Asociación Latinoamericana de Sociología, UNAM, Coordinación de Humanidades, 1996.

TEIXEIRA, Francisco J.S., e OLIVEIRA, Manfredo Araújo de (org). Neoliberalismo E Reestructuração Produtiva. São Paulo: Cortez; Fortaleza: UEC, 1996.

WALLERSTEIN, Immanuel. La reestructuración capitalista y el sistema mundo. In: SOSA ELÍZAGA, Raquel (coord.). América Latina y el Caribe: perspectivas de su reconstrucción. México: Asociación Latinoamericana de Sociología, UNAM, Coordinación de Humanidades, 1996. 


\section{Resumo}

O artigo analisa varias caraterísticas atuais das ciências sociais latino-americanas em paralelo ao desenvolvimento da América Latina nos últimos anos. O ponto de partida é o sinal de que a combinação contraditória no continente latino-americano entre uma intelectualidade que tem um elevado nível cultural e a existência de movimentos sociais e políticos numa situação social explosiva, gera amplas possibilidades para o desenvolvimento da sociologia. A crise das ciências sociais acompanha estas mudanças significativas, na busca de novas perspectivas analíticas capazes de explicar o ritmo de mudanças contemporâneas.

A rigor, no artigo, tenta-se demonstrar que o que a sociologia latino-americana tem como novo é um regresso ao pensamento crítico que a caracterizou no passado. Uma das mais importantes heranças da história sociológica latino-americana é o estudo e a classificação, desde uma perspectiva de totalidade, das estruturas sociais e dos processos sociopolíticos como fundamento para analisar o posicionamento dos atores e a dinâmica das instituições sociais.

Assim, abre-se espaço para uma saudável tendência nas ciências sociais: superar o empirismo, reencontrando-se com a teoria. Uma necessidade fundante, hoje, para a América Latina é atualizar a sua procura de desenvolvimento: como estar à altura do mundo, como universalizar-se para viver o momento histórico atual com todas as potencialidades sociais possíveis, superando formas de produção e de vida atrasadas e caducas. E mais: como co-participar na crítica das novas formas modernas e pós-modernas, vislumbrando novos modelos de civilização, fazendo a crítica da democracia liberal e dos Estados nacionais de concorrência de latino-americanos, e impulsionando a recuperacão do público democrático perante a tendência ao autoritarismo estatal.

Os aportes que a América Latina pode dar à crítica e à renovação da democracia política, à reforma da produção e da vida, ao humanismo e ao comunitarismo radical renovado, têm que se encontrar com os velhos objetivos de libertação nacional e social do mundo atual, adaptados às novas condições.

Palavras-chaves: América Latina, Sociología latino-americana, empirismo, teoria social, civilização, crise política, democracia, exclusão, Estado neoliberal, sociedade civil, público estatal. 


\section{Novelty in Latin American sociology}

\section{Lucio Oliver Costilla}

The paper examines several current characteristics of social sciences in Latin America, in parallel to the development of the subcontinent in recent years. The starting point is the sign that the contradictory combination in Latin America of an intellectuality that has a high cultural level and the existence of social and political movements in an explosive social situation creates wide possibilities for the development of sociology. The crisis of social sciences follows those significant changes, seeking new analytical perspectives able to demonstrate the pace of contemporary changes.

Strictly speaking, the article tries to demonstrate that what Latin American sociology sees as novelty is a regression to the critical thinking that characterized it in the past. One of the most important legacies of Latin American sociological history is the study and classification, from a perspective of totality, of social structures and sociopolitical processes as a basis to examine actors' stances and the dynamics of social institutions.

Therefore, there is room for a healthy trend in social sciences: overcoming empiricism, regaining theory. A founding need for Latin America today is to update its search for development: how is it possible to be up to the world, to universalize in order to live a historical moment with all its social potential, overcoming backwards and age-worn ways of production and life. And more: how to coparticipate in the criticism of new modern and postmodern ways, envisaging new models of civilization, criticizing liberal democracy and Latin Americans' national States of competition, and encouraging the recovery of the democratic public in face of the tendency to state authoritarianism.

The contributions that Latin America can give to the criticism and the renewal of democratic politics, to the reform of production and life, and to humanism and renewed radical communitarianism have to meet the old aims of national and social liberation of today's world, adjusted to the new conditions.

Key words: Latin America, Latin American sociology, empiricism, social theory, civilization, political crisis, democracy, exclusion, neoliberal State, civil society, State public. 